\title{
INHAL'T.
}

Geschichtliche Einleitung . . . . . . . . . . . . . VII-LVI

\section{Begutachtete Fälle.}

I. Fall Dohlhofr (Geltner):

Kaiserschnitt statt Bauchschnitt . . . . . . . . . . 1

II. Fall Dohlhofy (PaUli):

Ein Brechmittel bei einer Gebärenden . . . . . . . . 47

III. Fall Bergmann:

Ein Pistolenschuss als Heilmittel . . . . . . . . . . . 85

IV. Fall Krrchgässer :

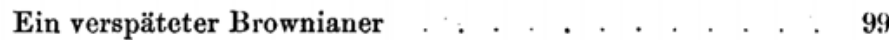

V. Fall Simpuan :

Absolut oder nur individuell tödtlich? . . . . . . . . . 159

VI. Fall Nuese:

Todtschlag bei zweifelhafter Zurechnungsfähigkeit . . . 169

VII. Fall von KNOBELSDorF :

Lebensversicherung eines Schwindsüchtigen . . . . . . 185

VIII. Fall Döring und Genossen:

Absolute oder zufällige Lethalität? $\quad$. . . . . . . . . . . . 199

IX. Fall KLEIN :

Mordversuch bei zweifelhafter Zurechnungsfähigkeit . . . 221

X. Fall Claasen :

Erdrosselung oder Selbstmord? . . . . . . . . . . . 247

XI. Fall SETz:

Todtschlag oder hinzugekommener Kunstfehler? . . . . 309

XII. Fall Fischer und Genossen:

War der Kaiserschnitt gerechtfertigt und kunstgerecht? . 333

XIII. Fall FrIEDRICH:

Durch Vernachlässigung tödtliche Verletzung ～. . . . . . 429

XIV. Fall IÜNNEBIER:

Die Zurechnungsfähigkeit einer 15jährigen Brandstifterin . 437 
